\title{
Diurnal variation of salivary oxidative stress marker 8-hydroxyguanine
}

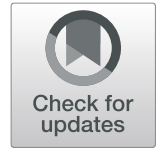

Sintaroo Watanabe ${ }^{1,2+}$, Yuya Kawasaki $^{1 \dagger}$ and Kazuaki Kawai ${ }^{1 *}$ (D)

\begin{abstract}
Introduction: Oxidative stress is a risk factor for life-style related diseases, including cancer. We recently reported that the oxidative stress marker 8-hydroxyguanine (8-OHGua) can be measured in saliva non-invasively. Understanding the diurnal pattern of salivary 8-OHGua levels is crucial for evaluating the oxidative stress. In this study, we analyzed the diurnal variation of salivary 8-OHGua levels.

Findings: The salivary 8-OHGua levels were relatively stable in the daytime (10:00-22:00). The daytime 8-OHGua levels seemed to represent the individual oxidative stress status. The average amount and the variation of the salivary 8-OHGua levels immediately after awakening were higher than those of the daytime levels.

Conclusions: The 8-OHGua levels in saliva exhibited diurnal variation. The levels were higher at the time of awakening. At this point, the daytime levels of salivary 8-OHGua may be appropriate for evaluating the individual oxidative stress status. Further study is needed for understanding and utilizing the 8-OHGua levels at the time of awakening.
\end{abstract}

Keywords: Oxidative stress, 8-hydroxyguanine (8-OHGua), Saliva, Diurnal variation

\section{Introduction}

Oxidative stress is a known risk factor for lifestyle-related diseases, such as cancer $[1,2]$. As a representative oxidative stress marker, 8-hydroxy-2'-deoxyguanosine (8$\mathrm{OHdG}$ ), an oxidative damage marker for nucleobases, has been widely analyzed using urine as a specimen. Urinary 8-OHdG measurement and oxidative stress evaluation may contribute to the prevention of lifestyle-related diseases. In addition to urinary $8-\mathrm{OHdG}$, we have found that salivary 8-hydroxyguanine (8-OHGua) might be useful as a new oxidative stress marker [3], because saliva can be collected more easily than urine. On the other hand, some salivary biomarkers, such as cortisol [4] and alpha-amylase $[5,6]$, show diurnal variations. Grew et al. [7] reported that the urinary $8-\mathrm{OHdG}$ levels did not show diurnal variation. However, little is known about the diurnal variation of salivary 8-OHGua. In order to use salivary 8-OHGua as an oxidative stress biomarker, it is crucial to establish its diurnal pattern. The aim of the present study is to

\footnotetext{
* Correspondence: kkawai@med.uoeh-u.ac.jp

+Sintaroo Watanabe and Yuya Kawasaki contributed equally to this work.

${ }^{1}$ Department of Environmental Oncology, Institute of Industrial Ecological

Sciences, University of Occupational and Environmental Health, Japan, 1-1

Iseigaoka, Yahatanishi-ku, Kitakyushu 807-8555, Japan

Full list of author information is available at the end of the article
}

investigate the diurnal variation of salivary 8 -OHGua and examine the appropriate time of saliva collection for the oxidative stress evaluation.

\section{Materials and methods \\ Saliva collection}

Ten minutes after rinsing the month with water, $2 \mathrm{~mL}$ of saliva were directly collected into a polypropylene tube from 6 subjects ( 4 male and 2 female), aged 20-60. The collected saliva samples were frozen at $-20^{\circ} \mathrm{C}$ until analysis. At the time of analysis, a $300 \mu \mathrm{L}$ portion of thawed saliva was mixed with $15 \mu \mathrm{L}$ of proteinase K (Wako Pure Chemicals, Tokyo, Japan), at a concentration of $20 \mathrm{mg} /$ $\mathrm{mL}$. The mixture was incubated at $37^{\circ} \mathrm{C}$ for $1 \mathrm{~h}$. After drying with a vacuum centrifuge for $12 \mathrm{~h}, 300 \mu \mathrm{L}$ of diluent $(1.8 \%$ acetonitrile, $62 \mathrm{mM}$ sodium acetate, $0.01 \mathrm{mM}$ sulfuric acid) was added. The samples were clarified with a centrifugal filter (Amicon Ultra Ultracel-10 K, Merk Millipore Ltd., Darmstadt, Germany). The 8-OHGua level was analyzed with an HPLC-ECD system, using $20 \mu \mathrm{L}$ of the filtrate as the sample. The 8-OHGua level was analyzed with a column switching HPLC-ECD system, using $20 \mu \mathrm{L}$ of the filtrate as the sample [3]. The HPLC was equipped with an anion exchange column

(c) The Author(s). 2019 Open Access This article is distributed under the terms of the Creative Commons Attribution 4.0 International License (http://creativecommons.org/licenses/by/4.0/), which permits unrestricted use, distribution, and 


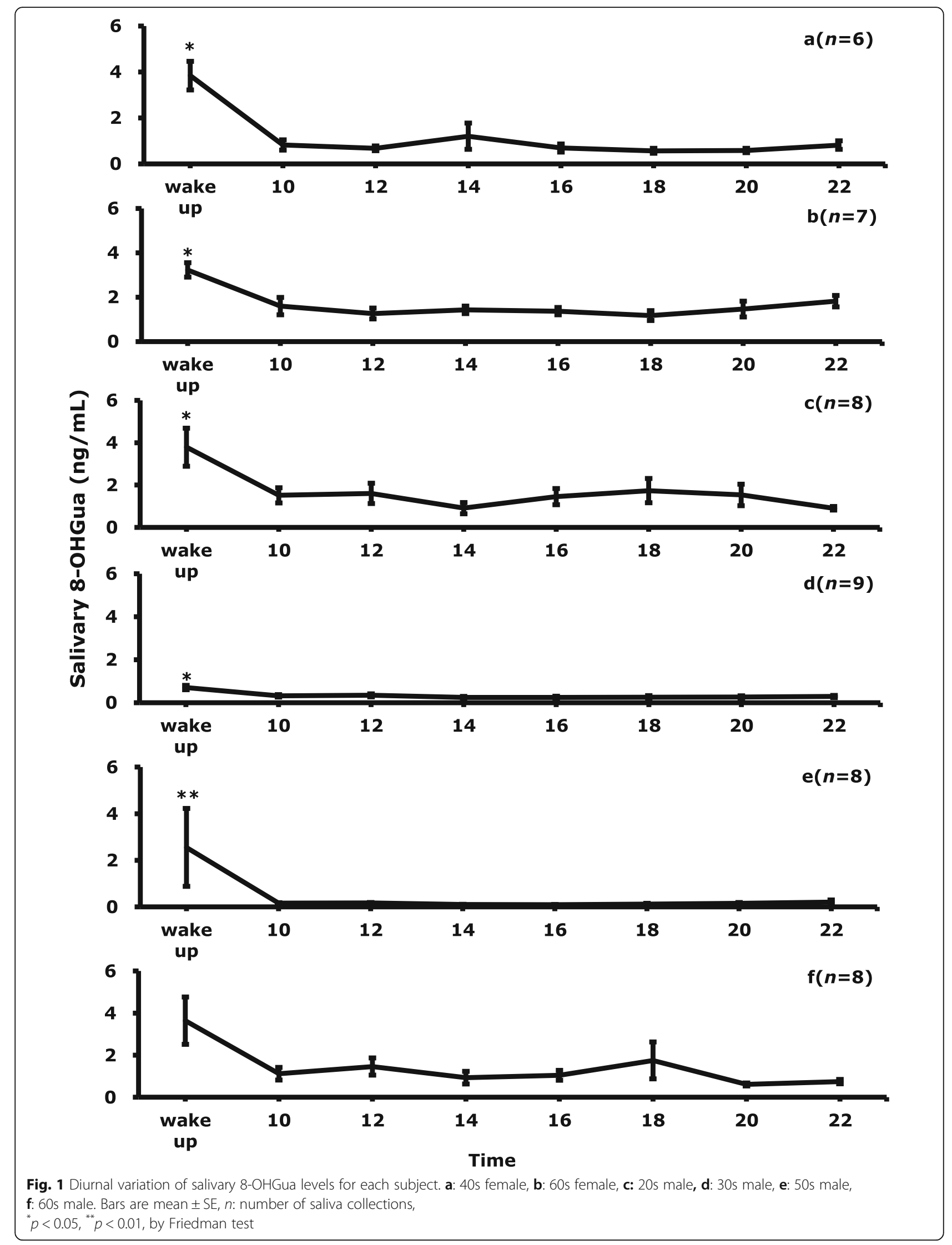


(MCI GEL CA08F, $7 \mu \mathrm{m}, 1.5 \times 30 \mathrm{~mm}+1.5 \times 90 \mathrm{~mm}$, solvent A, $60 \mu \mathrm{L} / \mathrm{min}$ ) and reverse phase column (GL Sciences, InertSustain C18, $3 \mu \mathrm{m}, 4.6 \times 250 \mathrm{~mm}$, solvent $\mathrm{B}, 0.6 \mathrm{~mL} / \mathrm{min})$. Solvent A was $2 \%$ acetonitrile in $0.3 \mathrm{mM}$ sulfuric acid, and solvent B was $9 \mathrm{mM} \mathrm{K} \mathrm{HPO}_{4}, 25 \mathrm{mM}$ $\mathrm{KH}_{2} \mathrm{PO}_{4}, 0.5 \mathrm{mM}$ EDTA.2Na, and $2.5 \%$ acetonitrile. According to the 8-OHGua standard solution, the coefficient of variation of the 8-OHGua level was within $5 \%$.

\section{Statistical analyses}

For statistical analysis, EZR (Jichi Medical University Saitama Medical Center Management, free software) was used [8]. The salivary 8-OHGua levels of each individual and the 6 subjects together were investigated at each collection time by the Friedman test. The statistical significance level was set at $p<0.05$.

\section{Results}

The diurnal changes of salivary 8-OHGua levels at the time of awakening and every $2 \mathrm{~h}$, from 10:00 to 22:00, are shown in Fig. 1. Each point represents the mean level of 6-9 samples collected on different days. The salivary 8-OHGua levels were significantly higher at the time of awaking, as compared to the other time points. There were no significant differences in the 8-OHGua levels in saliva between 10:00 and 22:00. It seems that each person has an individual characteristic value, except for at the time of awakening. Although the number of subjects was limited, the diurnal profile of 8-OHGua did not differ between male and female. The diurnal variation of the salivary 8-OHGua levels for all subjects is shown in Fig. 2. The average level of salivary 8-OHGua immediately after awakening was about three-fold higher than that of the other time periods. In addition, the standard error of the salivary 8-OHGua levels was about twice as high at the time of awakening, as compared to the case of the samples obtained at the other time periods.

\section{Discussion}

The present study revealed that the salivary 8-OHGua level upon awakening was higher than those during the daytime, and remained relatively stable during the day. Some salivary biomarkers show circadian variations. For example, the salivary $\alpha$-amylase activity is reportedly low from night to dawn and high during the day [6,9]. In contrast, the levels of melatonin [10], cortisol [4], chromogranin A (CgA) [4], and secretory globulin A (sIgA) [11] in saliva were high from night to dawn and low during the day. Salivary cortisol [12], one of the potential biomarkers for mental stress, showed similar diurnal variations to the 8 -OHGua. Salivary 8 -OHGua would be expected as a potential stress marker in industrial settings. Although the detailed mechanism remains unknown, the involvement of clock genes was suggested as the mechanism underlying the diurnal variation of the melatonin and sIgA levels. The sympathetic nerve activity was also suggested as the mechanism for the diurnal variation of the CgA levels. In addition, the salivary flow rate was involved in the diurnal variation of the secretion of antidiuretic hormone $(\mathrm{ADH})$, because the secretion of $\mathrm{ADH}$ is increased at night and $\mathrm{ADH}$ suppresses salivary secretion [13]. In this study, although the flow rate of the saliva was not measured at each sampling point, the subjects did not report any difference in the flow rate in the morning, as compared to the rest of the day. The effect of the salivary flow rate on the 8-OHGua level may be limited. The higher amount of salivary 8OHGua at the time of awakening may reflect a causal effect of the characteristic diurnal variation of saliva. Previous analyses revealed that the other oxidative stress marker, urinary 8-OHdG, does not show diurnal variation [7]. The subjects rinsed their mouths before saliva collection, but the samples could still be contaminated with a small amount of blood [14]. This might also affect the salivary 8-OHGua level. To confirm the value of the salivary 8-OHGua as an oxidative stress marker, future comparisons with other oxidative stress markers, such as

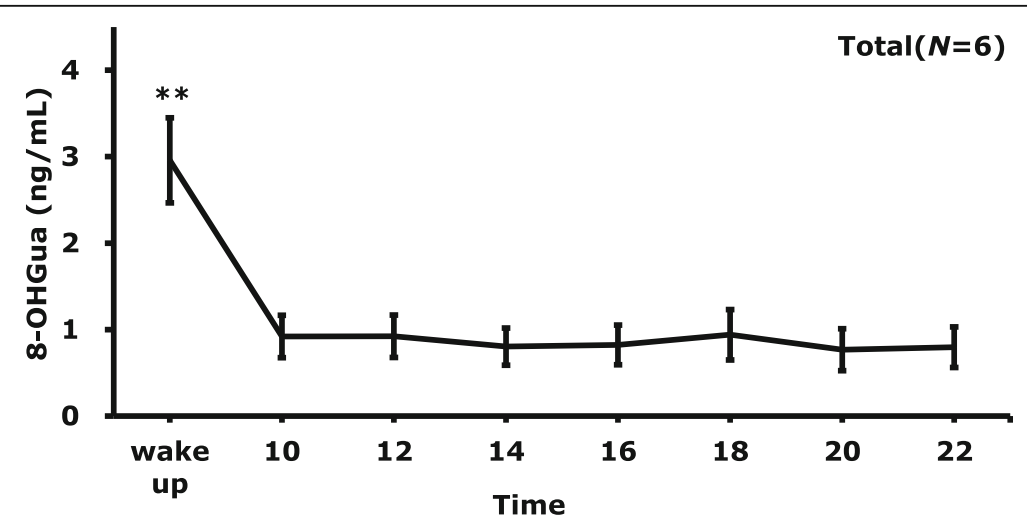

Fig. 2 Diurnal variation of salivary 8-OHGua levels for all subjects $(N=6)$. Bars are mean $\pm S E_{,}^{* *} p<0.01$, by Friedman test 
urinary 8-OHdG, will be made with the same subject. Recently, we reported that the salivary 8-OHGua levels were significantly elevated with age, smoking, hypertension, and excess visceral fat [15]. In the report, saliva samples were collected in the morning (8 a.m. - 11 a.m.). It may be more appropriate to collect the saliva during the day, for evaluations of the salivary 8-OHGua levels to assess the oxidative stress status. Further examination is needed to reveal the meaning of the higher level and of salivary 8-OHGua at the time of awakening.

\section{Abbreviations}

8-OHdG: 8-hydroxy-2'-deoxyguanosine; 8-OHGua: 8-hydroxyguanine; ADH: antidiuretic hormone; CgA: chromogranin A; ECD: electrochemical detector; slgA: secretory immunoglobulin A

\section{Acknowledgements}

We thank Dr. Hiroshi Kasai for helpful advice about the 8-OHGua measurement.

\section{Authors' contributions}

SW and YK contributed equally to this study. SW, YK, and KK collected the samples and analyzed saliva samples. SW statistically analyzed the data. KK and SW designed and critically discussed the study. All authors read and approved the final manuscript.

\section{Authors' information}

Not applicable.

\section{Funding}

This work was supported by JSPS KAKENHI Grant Number JP17H01908 and Industrial Disease Clinical Research Grant 170701-01.

\section{Availability of data and materials}

All data generated or analyzed during this study are included in this published article.

\section{Ethics approval}

The study was approved by the Ethics Committee of Medical Research University of Occupational and Environmental Health, Japan.

\section{Consent for publication}

Not applicable.

\section{Competing interests}

The authors declare that they have no competing interests.

\section{Author details}

'Department of Environmental Oncology, Institute of Industrial Ecological Sciences, University of Occupational and Environmental Health, Japan, 1-1 Iseigaoka, Yahatanishi-ku, Kitakyushu 807-8555, Japan. ${ }^{2} J a p a n$ Marine United Corporation Kure Shipyard, 2-1 Showa-cho, Kure-shi 737-0027, Japan.

Received: 31 October 2019 Accepted: 25 November 2019

Published online: 10 December 2019

\section{References}

1. Kasai H, Kawai K. 8-Hydroxyguanine, an oxidative DNA and RNA modification. In: Jurga S, Erdmann VA, Barciszewski J, editors. Modified nucleic acids in biology and medicine. Cham: Springer International Publishing; 2016. p. 147-85.

2. Kasai H. What causes human cancer? Approaches from the chemistry of DNA damage. Genes Environ. 2016;38:19. https://doi.org/10.1186/s41021016-0046-8.

3. Kawai K, Kasai H, Li YS, et al. Measurement of 8-hydroxyguanine as an oxidative stress biomarker in saliva by HPLC-ECD. Genes Environ. 2018;40:5. https://doi.org/10.1186/s41021-018-0095-2.
4. Den R, Toda M, Nagasawa S, Kitamura K, Morimoto K. Circadian rhythm of human salivary chromogranin a. Biomed Res. 2007;28:57-60.

5. Rohleder N, Nater UM, Wolf JM, Ehlert U, Kirschbaum C. Psychosocial stressinduced activation of salivary alpha-amylase: an indicator of sympathetic activity? Ann N Y Acad Sci. 2004;1032:258-63.

6. Nater UM, Rohleder N, Schlotz W, Ehlert U, Kirschbaum C. Determinants of the diurnal course of salivary alpha-amylase. Psychoneuroendocrinology. 2007;32:392-401.

7. Grew IS, Cejvanovic V, Broedbaek K, Henriksen T, Petersen M, Andersen JT, Jimenez-Solem E, Weimann A, Poulsen HE. Diurnal variation of urinary markers of nucleic acid oxidation. Scand J Clin Lab Invest. 2014;74:336-43.

8. Kanda Y. Investigation of the freely available easy-to-use software 'EZR' for medical statistics. Bone Marrow Transplant. 2013;48:452-8.

9. Marchand A, Juster R-P, Lupien SJ, Durand P. Psychosocial determinants of diurnal alpha-amylase among healthy Quebec workers. Psychoneuroendocrinology. 2016;66:65-74.

10. Voultsios AF, Kennaway DJ, Dawson D. Salivary melatonin as a circadian phase marker: validation and comparison to plasma melatonin. J Biol Rhythm. 1997;12:457-66.

11. Shirakawa T, Mitome M, Oguchi H. Circadian rhythms of S-IgA and cortisol in whole saliva. Compensatory mechanism of oral immune system for nocturnal fall of saliva secretion. Pediatr Dent J. 2004;14:115-20.

12. Hellhammer DH, Wüst $\mathrm{S}$, Kudielka BM. Salivary cortisol as a biomarker in stress research. Psychoneuroendocrinology. 2009;34:163-71.

13. Dawes C. Circadian rhythms in human salivary flow rate and composition. J Physiol. 1972;220:529-45.

14. Sugimura $\mathrm{H}$, Yamamoto $\mathrm{H}$, Watabiki $\mathrm{H}$, et al. Correlation of detectability of hepatitis $\mathrm{C}$ virus genome in saliva of elderly Japanese symptomatic HCV carriers with their hepatic function. Infection. 1995;23:258-62.

15. Watanabe S, Kawasaki Y, Kawai K. Salivary 8-hydroxyguanine as a lifestyle-related oxidative stress biomarker in workers. J Clin Biochem Nutr. 2020; In press

\section{Publisher's Note}

Springer Nature remains neutral with regard to jurisdictional claims in published maps and institutional affiliations.

\section{Ready to submit your research? Choose BMC and benefit from:}

- fast, convenient online submission

- thorough peer review by experienced researchers in your field

- rapid publication on acceptance

- support for research data, including large and complex data types

- gold Open Access which fosters wider collaboration and increased citations

- maximum visibility for your research: over $100 \mathrm{M}$ website views per year

At BMC, research is always in progress.

Learn more biomedcentral.com/submissions 